\section{Biopolíticas do aleitamento materno: uma análise dos movimentos global e local e suas articulações com os discursos do desenvolvimento social}

\author{
Biopolitics for breastfeeding: an analysis of the \\ global and local movements and their links \\ to social development discourses
}

\author{
Biopolíticas en lactancia materna: análisis \\ de movimientos globales y locales y sus \\ interrelaciones con discursos de \\ desarrollo social
}

Alessandra Rivero Hernandez 1
Ceres Gomes Víctora 1,2

\section{Resumo}

Este artigo tem como objetivo analisar as articulações entre a produção das biopoliticas de amamentação e os discursos produzidos sobre desenvolvimento social após o período pós-guerra com vistas à problematização da dicotomia natureza/cultura mediante a qual a amamentação é frequentemente operada. Numa perspectiva antropológica, examinaram-se as biopoliticas de amamentação comparativamente às transformações nos discursos desenvolvimentistas. $O$ exame dos movimentos globais realizadas por essas biopoliticas permitiu compreender como uma rede de entidades variadas (como órgãos de governo, organismos multilaterais, agências internacionais de desenvolvimento e organizações não governamentais) vem configurando ao longo do tempo a amamentação em conformidade com os discursos e práticas desenvolvimentistas em vigor. Inicialmente, o discurso desenvolvimentista girava em torno da industrialização e modernização, e a amamentação não era foco de atenção das políticas públicas. Nas décadas de 1970 e 1980, quando o discurso desenvolvimentista passou a focar a desnutrição e a mortalidade infantil, têm início as primeiras biopoliticas globais de amamentação e a prática da amamentação passa a ser operada como um meio de combater tais males. Já o discurso de desenvolvimento social em jogo na contemporaneidade evoca também um processo de desenvolvimento individual. Simultaneamente, as biopoliticas de amamentação recorrem a tecnologias variadas com este propósito. Conclui-se que os discursos desenvolvimentistas atuam como uma referência sociocultural com base na qual a amamentação é operada, o que permite dizer que a amamentação é uma prática tão natural quanto política, econômica e social. doi: 10.1590/0102-311X00155117

\author{
Correspondência \\ A. R. Hernandez \\ Av. Grécia 1000, apto. 1802B, Porto Alegre, RS 91350-070, \\ Brasil. \\ riverohernandez@hotmail.com \\ 1 Núcleo de Antropologia do Corpo e da Saúde, Universidade \\ Federal do Rio Grande do Sul, Porto Alegre, Brasil. \\ 2 Departamento de Antropologia, Universidade Federal do Rio \\ Grande do Sul, Porto Alegre, Brasil.
}




\section{Introdução}

Nos últimos quarenta anos, todo um conjunto de políticas públicas de saúde voltadas para a promoção, proteção e apoio da amamentação tem sido implementado tanto em escala mundial quanto nacional. No presente trabalho, essas políticas públicas são problematizadas enquanto biopolíticas. Em seus estudos sobre a genealogia do poder, Michel Foucault 1 chama a atenção para $\mathrm{o}$ aparecimento na segunda metade do século XVIII de uma nova técnica de poder que não substituiu totalmente a técnica disciplinar, que nomeia de biopolítica. Enquanto a técnica disciplinar opera no âmbito das instituições (escolas, prisões, hospitais, quartel, fábricas etc.) e se dirige ao corpo individual, que deve ser vigiado, treinado e ocasionalmente punido, a biopolítica é dirigida às populações e atua via uma série de intervenções reguladoras dos processos próprios da vida, como nascimento, morte, reprodução e doença. O conceito de biopolítica é analiticamente profícuo, segundo Paul Rabinow \& Nikolas Rose 2 , na medida em que chama a atenção para três aspectos articulados entre si: (1) um ou mais discursos de verdade sobre os seres vivos e um conjunto de autoridades consideradas competentes para falar aquela verdade; (2) as estratégias de intervenção sobre a existência coletiva em nome da vida e da morte; e (3) os modos de subjetivação, através dos quais os indivíduos são levados a governar a si próprios, em nome da vida ou da saúde individual ou coletiva.

O objetivo deste artigo é analisar as articulações entre a produção dessas biopolíticas e os discursos produzidos historicamente sobre desenvolvimento social e econômico após a segunda guerra mundial. Embora a existência de biopolíticas de aleitamento materno date de período anterior dentro e fora do Brasil 3,4,5, considerou-se que, a partir desse momento, surgem entidades supranacionais e uma nova configuração mundial que produzem reverberações nas biopolíticas de amamentação e as expandem para além das fronteiras nacionais. De acordo com Arturo Escobar 6, as noções de "subdesenvolvimento" e "terceiro mundo" são produtos discursivos dessa época, não existindo anteriormente. Em tal período, uma nova ordem geopolítica foi conformada, pela hierarquização de diferenças, expressas em termos como primeiro/terceiro mundo, norte/sul, centro/periferia e desenvolvido/subdesenvolvido. A partir de então, a implementação de estratégias de intervenção em países de "terceiro mundo" passaria a ser justificada em nome do desenvolvimento social. Uma questão discutida pelo antropólogo colombiano, e relevante para o presente trabalho, são as transformações dos discursos desenvolvimentistas ao longo do tempo. Enquanto as estratégias desenvolvimentistas operadas nas décadas de 1940 e 1950 se assentavam em um discurso que tinha como premissa o desenvolvimento via modernização e industrialização, durante as décadas de 1970 e 1980, a fome e a desnutrição passaram a ser vistas como empecilhos para o desenvolvimento social e uma série de políticas de alimentação e nutrição foi implementada. Ainda, a partir dos anos 1980, uma nova formação discursiva do desenvolvimento social passou a incluir os campesinos, as mulheres e o meio ambiente 6 .

\section{Metodologia}

A presente discussão é orientada pela perspectiva antropológica, empreendendo uma análise comparativa e relativista. Nesse sentido, parte-se do estranhamento quanto aos (familiares) modos como o aleitamento materno vem sendo configurado, em nível global, desde o período pós-guerra para mostrar como eles são efeito dos discursos e das práticas desenvolvimentistas acionados pelas biopolíticas de amamentação. Assim, busca-se problematizar a dicotomia natureza/cultura em que se pautam comumente os discursos sobre amamentação/desmame, por meio duma concepção biologizante dessa prática, que foi promovida pelo movimento higienista no século XIX e que perdura até hoje 4 . Cotejando com as transformações dos discursos desenvolvimentistas ao longo do tempo abordadas por Escobar, foi realizada análise de documentos e materiais 7,8,9,10,11,12,13,14,15 produzidos no âmbito das biopolíticas globais de amamentação, ou mesmo a ausência delas. Para dar conta das transformações ocorridas nas biopolíticas de amamentação mais notadamente nos anos 2000, fez-se necessário recorrer a outros autores que esclarecessem os sentidos atribuídos ao conceito de desenvolvimento social a partir de então.

Interessava também conhecer os atores envolvidos na produção e propagação das biopolíticas de amamentação do global para o local e vice-versa. Para tanto, complementou-se a análise com 
trabalhos 16,17,18,19,20 que, ao serem examinados em conjunto, permitiram vislumbrar a atuação ao longo do tempo de uma ampla rede constituída por múltiplas entidades. Dentre elas, encontram-se, entre outros, órgãos de governo, organismos multilaterais, agências internacionais de desenvolvimento, organizações não-governamentais (ONGs), profissionais da saúde e pesquisadores envolvidos na promoção e elaboração das biopolíticas de amamentação. Argumenta-se que essa rede não apenas tem um papel fundamental na circulação transnacional das biopolíticas de amamentação, como também vem configurando ao longo do tempo a amamentação em conformidade com os discursos e práticas desenvolvimentistas em vigor.

A apresentação e discussão dos achados serão explanadas neste artigo de modo concomitante em três tópicos, apresentados a seguir. No primeiro, descrevem-se as primeiras articulações entre a prática da amamentação e o discurso do desenvolvimento social impelidas na década de 1970 por organizações que inicialmente não tinham como objeto o aleitamento materno, mas o desenvolvimento dos chamados países de "terceiro mundo". Vincula-se o surgimento de um movimento globalizado em torno da amamentação com uma mudança no discurso desenvolvimentista, que se volta para o combate da fome e da desnutrição infantil. No segundo tópico, é apresentada a produção e difusão de variadas estratégias de intervenção em movimentos tanto do global para o local como do local para o global, da década de 1980 à atualidade, operacionalizados por uma rede de entidades que iria se estabilizar a partir de então. Passam a fazer parte dessa rede, ONGs que têm o aleitamento materno como expertise e que participam na elaboração, implementação e avaliação de diversas dessas biopolíticas. A incorporação de novos discursos desenvolvimentistas possibilita configurar a amamentação em outros termos. No terceiro tópico, dá-se atenção ao surgimento na formulação dessas biopolíticas de modos de subjetivação pautados na retórica da escolha e do engajamento individual, em consonância com os discursos mais atuais do desenvolvimento social. É importante ressaltar que as práticas de amamentação passam a se constituir mais intensamente nessa época como uma forma de empoderamento feminino, e, em consonância com isso, o aconselhamento em amamentação é fomentado como forma de atuação profissional junto à mulher em várias das biopolíticas de amamentação. Alguns trabalhos 21,22 destacam o fato de essa técnica propiciar que a mulher tome decisões por si mesma a respeito da alimentação do seu bebê. Portanto, um questionamento relevante que, por constrangimento de espaço não poderá ser contemplado, diz respeito a como práticas de empoderamento feminino convivem com formas sistemáticas de exercício da autoridade sobre o corpo da mulher.

\section{As organizações desenvolvimentistas e a produção de conexões globais em torno da amamentação}

O movimento globalizado em prol da amamentação teve início na década de 1970, quando ganharam força as afirmações sobre a relação do aumento da desnutrição infantil com o declínio da prática da amamentação provocado pela promoção comercial de fórmulas infantis destinadas à substituição ou complementação do leite materno. Não se tratava de uma relação inusitada, nunca antes pensada, pois ela já havia sido anunciada em décadas anteriores junto ao Rotary Club e em revistas especializadas por médicos pediatras atuantes em zonas de pobreza. A partir dessas denúncias, agências da Organização das Nações Unidas (ONU), como o Fundo das Nações Unidas para a Infância (UNICEF) e a Organização para Alimentação e a Agricultura (FAO), além de profissionais da saúde e representantes da indústria se reuniram no início dos anos 1970. A declaração resultante desse encontro não alterou muito o quadro, ou até mesmo pode tê-lo agravado, visto que considerou que os governos de países de terceiro mundo deveriam disponibilizar fórmulas infantis e alimentos para as crianças como forma de garantir sua alimentação ${ }^{16}$. Entretanto, nos anos seguintes, pela produção de conexões entre diferentes entidades, ocorreu uma mudança em favor da proteção da prática da amamentação que levou à regulação da promoção de fórmulas infantis. Frente a essa mudança, cabe perguntar o que tornou possível o envolvimento de diferentes entidades em um movimento globalizado em favor da amamentação que perdura até hoje? Que sentidos essa rede de entidades conferiu à prática da amamentação?

De acordo com a historização feita por Ellen Sokol 16, pode-se dizer que a intersecção entre promoção comercial de leite em pó, desmame e desnutrição infantil passou a ganhar visibilidade em 1973 com a publicação da matéria The Baby Food Tragedy pela revista britânica New Internacionalist. No ano 
seguinte, foi publicado o relatório The Baby Killer pela organização pró-desenvolvimento com sede em Londres (Inglaterra) War on Want. O relatório denunciava o impacto das práticas promocionais de fórmulas na alta da maternidade sobre a nutrição infantil e a economia de países de terceiro mundo, onde a população pobre não tinha acesso à água potável para misturar ao leite em pó ou acabava acrescentando farinha para fazê-lo render. Em seguida, o relatório foi traduzido para o alemão por um pequeno grupo suíço de estudantes de teologia, o Arbeitsgruppe Dritte Welt (Grupo de Ação para o Terceiro Mundo), que o renomeou de A Nestlé Mata Bebês. A empresa processou judicialmente o grupo por difamação em relação ao título do documento e, embora tenha ganhado a causa, o litígio não deixou de ser uma perda para a companhia, à medida que deu visibilidade à questão.

Nos anos seguintes, um grupo nos Estados Unidos chamado Infant Formula Action Coalition InFACT (uma organização sem fins lucrativos fundada pelo The Third World Institute e composta por nutricionistas, educadores, representantes religiosos e pessoas interessadas), promoveu via Igreja um boicote à empresa, ação que se espalhou para outros países, como Canadá, Austrália e Nova Zelândia. O grupo conseguiu junto a líderes congressistas a realização de audiências para discutir o tema publicamente. Porém, o senador americano Edward Kennedy atuou com intuito de deslocar o embate para um forum internacional em que pudesse ser discutido por autoridades governamentais, profissionais da saúde e peritos da indústria sem tanta pressão popular, o que rapidamente recebeu apoio dos representantes das empresas de alimentação infantil 16.

Assim, a Organização Mundial da Saúde (OMS) e o UNICEF realizaram a Reunião Conjunta sobre Alimentação de Lactentes e Crianças Pequenas na cidade de Genebra (Suíça), em 1979, com a participação de representantes de governos, ONGs, representantes da indústria e especialistas de diversas áreas relacionadas. A Reunião tirou como recomendação a elaboração do Código Internacional de Comercialização de Alimentos pata Lactentes, por avaliar que a alimentação infantil inadequada e suas consequências eram um sério entrave para o desenvolvimento social e econômico. Na Assembleia Mundial da Saúde (AMS) de 1981, o Código foi então votado e aprovado 16,17.

Como referido na introdução, os discursos desenvolvimentistas tornaram possível a produção de conexões entre organismos multilaterais, governos de países, ONGs, profissionais da saúde e pesquisadores em um movimento globalizado em torno da amamentação. Inicialmente, foram organizações desenvolvimentistas que trouxeram à tona outra perspectiva da questão da promoção de leite em pó, desnutrição e óbito infantil. No entanto, a promoção da prática da amamentação como um meio de viabilizar o desenvolvimento econômico e social daí em diante seria reiterada permanentemente por todos os entes dessa rede.

Essa mudança em favor da amamentação coincide com um deslocamento nos discursos e estratégias desenvolvimentistas que começaram a ser produzidos no período pós-guerra. De início, tais discursos se centraram no crescimento econômico via industrialização e modernização ${ }^{6}$. Cabe mencionar que, à época, o uso de fórmulas infantis e de mamadeira era promovido pela indústria como constitutivo de um estilo de criação infantil entendido como moderno, em consonância com os preceitos da Pediatria 23. Contudo, nos anos 1970 e 1980, o discurso desenvolvimentista passou a focar questões sociais e de saúde, dando origem a programas de alimentação e nutrição elaborados por especialistas 6. É nessa época que a amamentação passa a ser operada como uma estratégia ao combate à desnutrição e mortalidade infantil.

\section{Da promoção, proteção e apoio à prática da amamentação: ampliando as ações do global para o local e vice-versa}

O Brasil participou de toda a movimentação global em prol da amamentação desde os primeiros momentos, estando representado na Reunião Conjunta de 1979 pelo Instituto Nacional de Alimentação e Nutrição (INAN), vinculado ao Ministério da Saúde. Em 1981, essa autarquia lançou no país o Programa Nacional de Incentivo ao Aleitamento (PNIAM), do qual ficou a cargo até 1997 quando o INAN foi extinto e as ações de aleitamento materno passaram a ser executadas pela área técnica da saúde da criança. Dentre as diversas ações desempenhadas na década de 1980 em favor da amamentação no país, destaca-se a veiculação de grandes campanhas de promoção da amamentação encabeçadas pelo PNIAM 18. Outra ação realizada, seguindo a recomendação da AMS de 1981, foi a aprovação, 
em 1988, de um primeiro documento legal próprio elaborado à luz do Código Internacional, posteriormente revisado e denominado atualmente de Norma Brasileira de Comercialização de Alimentos para Lactentes, Crianças de Primeira Infância, Bicos, Chupetas e Mamadeiras (NBCAL) 19.

Ainda no final da década de 1980, a OMS e o UNICEF emitiram uma declaração conjunta conclamando as maternidades a seguirem os Dez Passos para o Sucesso da Amamentação, a fim de modificar no âmbito das maternidades as práticas profissionais que favoreciam o desmame, como a de manter os recém-nascidos em berçários. Dessa maneira, os organismos multilaterais passaram a atuar não apenas na regulamentação de fórmulas infantis, mas de uma maneira mais ampla também na educação de profissionais da saúde e nas rotinas dos serviços de saúde. Em 1990, foi aprovada a Declaração de Innocenti por representantes de organizações governamentais, ONGs e agências das Nações Unidas reunidos na Itália em encontro promovido pela OMS, UNICEF, United States Agency for International Development (USAID) e Agência Sueca de Desenvolvimento Internacional (SIDA). A declaração estabelecia metas e objetivos a serem cumpridos pelos países em até cinco anos, entre eles, colocar em prática os Dez Passos para o Sucesso da Amamentação 16. Com esse intuito, em 1991, foi lançada a Iniciativa Hospital Amigo da Criança (IHAC), que teve início no Brasil no ano seguinte 19.

Com objetivo de fazer valer a Declaração de Innocenti, diversas ONGs formaram a Aliança Mundial de Ações Pró-Amamentação (World Alliance for Breastfeeding Action - WABA) 16,20. Entre as ONGs que constituem a WABA, estão: Rede Internacional em Defesa do Direito de Amamentar (International Baby Food Action Network - IBFAN), que tem como principal objetivo monitorar o cumprimento da NBCAL; La Leche League International (LLLI), que congrega mulheres com experiência em amamentação que se disponham a ajudar gratuitamente outras mulheres a amamentarem; International Lactation Consultant Association (ILCA) é a associação de consultores em amamentação certificados pela International Board of Lactation Consultant Examiners (IBLCE); e Wellstart International, voltada para a capacitação de profissionais da saúde 19 . Desde sua concepção, a WABA instituiu a Semana Mundial da Amamentação (SMAM), celebrada de 1 a 7 de agosto. Os membros da WABA definem a cada ano um tema para ser trabalhado globalmente durante a SMAM, mas cada país pode adaptar a frase. No Brasil, a coordenação da SMAM ficou sob responsabilidade da Sociedade Brasileira de Pediatria (SBP) até 1999, quando passou a ser coordenada pelo Ministério da Saúde 18. Os temas propostos pela WABA estão relacionados ao seu objetivo de fazer valer a agenda pró-amamentação promovida pelas agências multilaterais e ONGs, ainda que na adaptação ao português isso se torne menos evidente (Tabela 1).

Isso fica claro ao se observarem os temas da SMAM em 1994 e em 2006, quando foi abordado o Código Internacional, ou em 2010, quando fez referência aos Dez Passos para o Sucesso da Amamentação. Nos materiais de divulgação da SMAM, elaborados pela WABA 8, tanto as biopolíticas quanto a prática da amamentação continuam a ser operadas como estratégias para o combate à desnutrição e à mortalidade infantil. Contudo, é possível perceber que elas também surgem articuladas à produção de novos discursos desenvolvimentistas. A amamentação passa a se configurar como meio para o empoderamento feminino em 1995 e para o alcance dos Objetivos de Desenvolvimento do Milênio (ODM) reiteradas vezes a partir de 2007. Ainda, constata-se uma ecologização da amamentação no discurso do desenvolvimento sustentável em 1997 e mais recentemente em 2016, após a adoção dos Objetivos de Desenvolvimento Sustentável (ODS) por 193 dos países membros das Nações Unidas no ano anterior.

Outra iniciativa no rol de políticas de promoção, proteção e apoio à amamentação é o Método Canguru. O Método Canguru foi criado no ano de 1979 em uma maternidade da cidade de Bogotá (Colômbia) em que, devido à superlotação na Unidade de Tratamento Intensivo (UTI) neonatal, eram postas mais de uma criança por incubadora, facilitando a difusão de infecções e o consequente aumento da mortalidade infantil. Ainda, a restrição de acesso dos pais ao local favorecia o desmame e o uso de fórmulas infantis, bem como dificultava o estabelecimento dos primeiros vínculos afetivos. $\mathrm{O}$ UNICEF apoiou financeiramente a implantação do Método Canguru na Colômbia e em outros países, contribuindo para levar a experiência local para um nível global. O primeiro serviço de saúde no Brasil a implantar o Método Canguru, no início da década de 1990, foi o Hospital Guilherme Álvaro, na cidade de Santos. Em 1997, o atualmente nomeado Instituto de Medicina Integral Professor Fernando Figueira (IMIP), situado em Recife, ficou entre os finalistas do concurso de projetos sociais realizado pela Fundação Ford e Fundação Getúlio Vargas e apoiado pelo Banco Nacional de Desenvolvimento Econômico e Social (BNDES), com o projeto Enfermaria Mãe Canguru. A partir de então, o Ministério 
Tabela 1

Cronologia de temas da Semana Mundial da Amamentação (SMAM), definidos pela World Alliance for Breastfeeding Action (WABA) e no Brasil, 1992-2017.

\begin{tabular}{|c|c|c|}
\hline Ano & WABA 8 & Brasil 7 \\
\hline 1992 & Baby-Friendly Hospital Initiative & Hospitais Amigos da Criança \\
\hline 1993 & Mother-friendly Workplace Initiative & Amamentação: direito da mulher no trabalho \\
\hline 1994 & Protect breastfeeding: making the Code work & Amamentação fazendo o Código funcionar \\
\hline 1995 & Breastfeeding - empowering women & Amamentação fortalece a mulher \\
\hline 1996 & Breastfeeding - a community responsibility & Amamentação responsabilidade de todos \\
\hline 1997 & Breastfeeding nature's way & Amamentar é um ato ecológico \\
\hline 1998 & Breastfeeding the best investment & Amamentação: o melhor investimento \\
\hline 1999 & Breastfeeding education for life & Amamentar: educar para a vida \\
\hline 2000 & Breastfeeding it's your right! & Amamentar é um direito humano \\
\hline 2001 & Breastfeeding in the information age & Amamentação na era da informação \\
\hline 2002 & Breastfeeding: healthy mothers and healthy babies & Amamentação: mães saudáveis, bebês saudáveis \\
\hline 2003 & Breastfeeding in a globalised world for peace and justice & Amamentação: trazendo paz num mundo globalizado \\
\hline 2004 & Exclusive breastfeeding: the gold standard safe, sound, sustainable & Amamentação exclusiva: satisfação, segurança e sorrisos \\
\hline 2005 & Breastfeeding and family foods & $\begin{array}{l}\text { Amamentação e introdução de novos alimentos a partir dos } 6 \\
\text { meses de vida. Do peito à comida caseira: saúde a vida inteira! }\end{array}$ \\
\hline 2006 & Breastfeeding code watch - 25 years of protecting & $\begin{array}{l}\text { Amamentação: garantir este direito é responsabilidade de todos. } \\
\text { O Código salva vidas - Atuemos já! }\end{array}$ \\
\hline 2007 & Breastfeeding: the 1st hour save one million babies! & Amamentação na primeira hora, proteção sem demora \\
\hline 2008 & Mother support: going for the gold & $\begin{array}{l}\text { Amamentação: participe e apoie a mulher! Se o assunto é } \\
\text { amamentar, apoio à mulher em primeiro lugar! }\end{array}$ \\
\hline 2009 & Breastfeeding: a vital emergency response & $\begin{array}{l}\text { Amamentação em todos os momentos: mais carinho, saúde e } \\
\text { proteção }\end{array}$ \\
\hline 2010 & Breastfeeding: just 10 steps! & $\begin{array}{c}\text { Amamente. Dê ao seu filho o que há de melhor. Amamentar é } \\
\text { muito mais que alimentar a criança. É um importante passo para } \\
\text { uma vida mais saudável }\end{array}$ \\
\hline 2011 & Talk to me! Breastfeeding - a 3D experience & $\begin{array}{l}\text { Amamentar faz bem para o bebê e para você. Até os seis meses, } \\
\text { o bebê só precisa de leite materno. Depois, ofereça alimentos } \\
\text { saudáveis e continue amamentando até os dois anos ou mais. } \\
\text { Informe-se, prepare-se. Torne essa experiência completa }\end{array}$ \\
\hline 2012 & Understanding the past-planning the future & Amamentar hoje é pensar no futuro \\
\hline 2013 & Breastfeeding support: close to mothers & $\begin{array}{c}\text { Tão importante quanto amamentar seu bebê é ter alguém que } \\
\text { escute você }\end{array}$ \\
\hline 2014 & Breastfeeding: a winning goal for life! & Amamentação. Um ganho para a vida toda. \\
\hline 2015 & Breastfeeding and work - let's make it work! & $\begin{array}{c}\text { Amamentação e Trabalho. Para dar certo o compromisso é de } \\
\text { todos }\end{array}$ \\
\hline 2016 & Breastfeeding: a key to sustainable development & Amamentação: faz bem para seu filho, para você e para o planeta \\
\hline 2017 & Sustaining breastfeeding together & $\begin{array}{l}\text { Amamentar: ninguém pode fazer por você. Todos podem fazer } \\
\text { juntos com você }\end{array}$ \\
\hline
\end{tabular}

da Saúde em parceria com o BNDES realizou ações de divulgação no país e outras maternidades implantaram o Método Canguru 9,10.

Em 1999, o Ministério da Saúde constituiu um grupo técnico formado por sociedades de classe profissional - Organização Pan-Americana da Saúde (OPAS), UNICEF, universidades brasileiras, secretarias estaduais da saúde, IMIP e BNDES - para elaboração das bases de uma política pública: a Norma de Atenção Humanizada ao Recém-Nascido de Baixo Peso - Método Canguru. Diferentemente do que em outros países onde o Método Canguru se configurou como uma alternativa mais barata à incubadora, no Brasil, ele foi constituído como uma biopolítica voltada para o cuidado de recém-nascidos 
prematuros de baixo peso que precisam permanecer em unidade de terapia intensiva neonatal ou unidade de cuidados intermediários neonatal. Dentre as mudanças nas rotinas que busca promover, estão: facilitar a entrada dos pais nesses locais, estabelecer gradativamente o contato pele a pele com o bebê, colocando-o na posição vertical junto ao peito (nomeada de posição canguru), bem como estimular a amamentação e a participação dos pais nos cuidados com o bebê 9,10 .

Assim como a experiência local da Colômbia com o Método Canguru foi disseminada para outros países, também o Brasil vem nos últimos anos difundindo sua expertise em bancos de leite humano (BLH), mas no caso brasileiro por intermédio de um programa bem estruturado de cooperação entre nações. Inicialmente, foi criada em 1998 a Rede Nacional de Bancos de Leite Humano (rBLH-BR) pelo Ministério da Saúde e encabeçada pelo BLH do Instituto Fernandes Figueira/Fundação Instituto Oswaldo Cruz (IFF/Fiocruz) (que é o serviço de referência no país), por meio da qual se buscou o compartilhamento de conhecimentos entre os BLH participantes. A Fiocruz investiu em pesquisas para o desenvolvimento de tecnologia própria, desde os frascos utilizados para armazenar o leite até os testes de controle e o maquinário para pasteurização, que anteriormente tinha de ser importado. Em 2001, a OMS concedeu à iniciativa o prêmio Sasawaka de saúde e a reconheceu como o trabalho que mais contribuiu para a redução da mortalidade infantil durante a década de 1990 e solicitou que essa experiência fosse compartilhada com outros países. Consequentemente, com apoio da OPAS, o país iniciou uma política de expansão junto a alguns países latino-americanos com os quais formou uma rede de cooperação técnico-científica. Ao longo dos anos a rede foi se ampliando, incorporou outros países das Américas, da África e da Península Ibérica, tornando-se em 2015 a Rede Global de Bancos de Leite Humano (rBLH) 11.

O Brasil também criou em 2008 uma biopolítica que amplia as ações de promoção, proteção e apoio à prática da amamentação para além do âmbito hospitalar. Denominada atualmente de Estratégia Amamenta e Alimenta Brasil (EAAB), após incorporar a questão da introdução de alimentos sólidos a partir do sexto mês de vida da criança, essa biopolítica visa à reorganização do trabalho e à transformação das práticas de profissionais atuantes nos serviços de atenção básica à saúde. Ainda, expandindo-se para o âmbito do trabalho, foi lançada em 2010 uma nova política que objetiva promover a instalação de salas de apoio à amamentação em empresas públicas e privadas. As salas de apoio à amamentação consistem em locais próprios para que funcionárias que estão amamentando possam retirar e estocar adequadamente seu leite durante a jornada de trabalho para posteriormente oferecê-lo a seu filho ou mesmo doar a um BLH.

\section{A produção das biopolíticas de amamentação e o discurso do desenvolvimento social via governo de si}

Além do discurso do desenvolvimento sustentável anteriormente referido, outra produção discursiva contemporânea do desenvolvimento social remete ao trabalho do economista indiano Amartya Sen. Sua tese se constitui como base dos relatórios de desenvolvimento humano anualmente editados a partir da década de 1990 pelo Programa das Nações Unidas para o Desenvolvimento (PNUD), assim como animaram a elaboração dos ODM 24. Para o ganhador do Prêmio Nobel de economia de 1998, o desenvolvimento social se relaciona com a "liberdade individual", com a expansão de "capacidades individuais" para a realização de escolhas e a ação. Nesse sentido, argumenta que as políticas públicas tanto têm o papel de fomentar a expansão de "capacidades individuais" como devem ser direcionadas pelo uso das "capacidades de participação" das pessoas 25.

Ao passo que o discurso desenvolvimentista volta-se para as "capacidades individuais", para realizar escolhas e se engajar ativamente, as biopolíticas de amamentação incorporam também essa questão. Nesse sentido, elas não devem ser entendidas somente como um meio para o desenvolvimento social via aumento dos índices de aleitamento materno no país, por mais que tal seja seu objetivo primeiro. Pois, como se busca salientar a seguir, essas biopolíticas vêm apresentando uma crescente disposição para aprimorar as capacidades de governar a si mesmo dos diferentes atores implicados, pelo uso de tecnologias variadas que têm em comum a retórica da escolha e da autonomia.

Algumas dessas tecnologias buscam ampliar as capacidades de gestão das informações e de tomada de decisão dos gestores de serviços de saúde e das equipes de profissionais de saúde. Desse modo, por 
exemplo, como parte do processo de implementação da IHAC, é oferecido aos gestores das maternidades interessadas um instrumento de autoavaliação que lhes permite realizar uma autoanálise das práticas desempenhadas pelo serviço e uma verificação da conformidade delas com os Dez Passos e a NBCAL. Somente após uma autoavaliação positiva é que avaliadores externos à maternidade, vinculados à Secretaria Estadual de Saúde e ao Ministério de Saúde, vão ao serviço de saúde para realizar nova avaliação no intuito de credenciar ou não o hospital como Amigo da Criança. No caso de uma autoavaliação negativa, espera-se que as maternidades desenvolvam, elas próprias, planos de ação a fim de adequar suas práticas ao preconizado pela IHAC antes de solicitar a realização de uma avaliação externa 12 .

Da mesma forma, para uma unidade básica de saúde pleitear a certificação na EAAB, é preciso inicialmente que ela preencha alguns critérios relacionados à autogestão desta biopolítica pela equipe de profissionais. Um desses critérios é que a equipe de profissionais desenvolva um plano de ação para incentivar o aleitamento materno e a alimentação complementar saudável. Outro critério é que ela monitore os índices de aleitamento materno e de alimentação complementar entre as crianças atendidas como meio para conhecer a situação local e direcionar a sua própria ação 13. Ainda, em certa medida, os compromissos e as metas internacionais (como é o caso dos ODM e dos ODS) adotados por diversos países pela assinatura de declarações promovidas pelas Nações Unidas também têm atuado como um mecanismo para a criação de biopolíticas de amamentação próprias no país, uma vez que, se as primeiras biopolíticas locais são replicações, adaptações ou inspiradas fortemente em ações definidas em escala global, mais recentemente elas têm coexistido com políticas inventadas localmente, levando em conta diretrizes globais para a ação, como é o caso da rBLH, da EAAB e das Salas de Apoio à Amamentação.

Outro conjunto de tecnologias se volta para o processo de aprendizagem das biopolíticas de amamentação pelos profissionais de saúde durante a realização de cursos e atividades. Pela utilização de diferentes metodologias ativas e recursos como dramatizações, dinâmicas de grupo e discussões coletivas, busca-se que os profissionais de saúde tenham uma atitude ativa na produção de conhecimentos. É o caso do Método Canguru que em seus cursos tanto de formação de tutores quanto de capacitação das equipes de profissionais atuantes em maternidades segue uma proposta de ensino-aprendizagem baseada em problemas. Sucintamente, pode-se dizer que esse método de aprendizagem promove que os próprios estudantes encontrem soluções para os problemas elencados mediante estudo individual, para posterior discussão em grupo ${ }^{14}$. Também é o caso da EAAB que tem a educação crítico-reflexiva como referencial teórico tanto das oficinas de formação de tutores quanto das oficinas de trabalho junto às equipes de atenção básica. Essa abordagem educativa pretende a "aprendizagem significativa”, de modo a favorecer, para além da simples aplicação do conteúdo aprendido em novas situações vivenciadas, o desenvolvimento de "habilidades de análise e síntese" dos educandos 13.

Um terceiro conjunto de tecnologias tem como foco a relação entre os profissionais de saúde e os pacientes. Transversal a várias das biopolíticas de amamentação, entre elas a IHAC e a EAAB, a técnica de aconselhamento em amamentação procura fomentar o autogoverno da usuária. Diferentemente do que o termo aconselhar pode levar a crer, praticar o aconselhamento não significa dar conselhos a alguém de como ele deveria pensar ou proceder. Pelo contrário, o aconselhamento parte do pressuposto de que pessoas, enquanto seres diferentes, respondem de modo distinto a mesma situação e, portanto, o papel do aconselhador diz respeito a contribuir para que esse alguém reflita sobre como se sente e atue conforme sua deliberação. A técnica se constitui de dois conjuntos de habilidades necessários para praticar o aconselhamento em amamentação. $\mathrm{O}$ primeiro conjunto de habilidades diz respeito a ouvir e aprender o que a mulher relata, buscando compreender a situação sem fazer julgamentos. O segundo conjunto de habilidades se refere aos meios pelos quais se busca aumentar a confiança e dar apoio à mulher, fornecendo informações que dialoguem com a situação e sugerindo (nunca ordenando) possíveis mudanças, a fim de que a mulher tome uma decisão informada sobre a alimentação de seu filho 15 .

A retórica da escolha promovida por essas variadas tecnologias se vincula aos "modos de subjetivação liberal” 2. E, embora seja formulada em oposição à ideia de obrigatoriedade e de atuar por determinação de terceiro, paradoxalmente, acaba por impor novas responsabilidades e obrigações. Especificamente em relação ao aconselhamento, tal técnica dialoga com a proposta de empoderamento feminino, à medida que o último pode ser pensado como uma potencialização da capacidade 
de fazer escolha com vistas ao aumento da autonomia das mulheres. Todavia, é necessário ter em conta que a possibilidade de a usuária fazer escolhas informadas surge no âmbito de uma estratégia de intervenção populacional que visa aumentar as taxas de aleitamento materno, assim como em um campo de práticas profissionais marcado pela herança higienista, que ainda se foca especialmente na saúde e na nutrição da criança e na responsabilização única da mulher pelo sucesso (ou não) da amamentação 4,26. Nesse contexto, cabe questionar se a estratégia mais atual para o estabelecimento de relações entre profissionais da saúde e usuárias do serviço não acaba se configurando como outra maneira menos evidente de instaurar o exercício da autoridade sobre o corpo da mulher 27.

\section{Conclusão}

Em suma, no presente artigo procurou-se elucidar como os discursos desenvolvimentistas proferidos a partir da segunda metade do século XX vêm tanto conformando as biopolíticas de alimentação infantil como dando novos sentidos a essa prática. Trata-se de configurações que tomam forma mediante atuação de uma rede de variadas entidades consideradas competentes para proferir discursos de verdade sobre a prática do aleitamento materno, que comumente são construídos com argumentos científicos. Tais argumentos se recobrem de um caráter universal, operando como referenciais "descontextualizados", o que vem ao encontro da proposta de se ter biopolíticas globais, ainda que elas frequentemente ressalvem a necessidade de se respeitar a diversidade cultural e as particularidades locais.

Assim, argumenta-se que, nas décadas de 1950 e 1960, quando o discurso desenvolvimentista girava em torno da industrialização e modernização, a amamentação (muitas vezes tida como uma prática natural e instintiva) não era foco de atenção das agências multilaterais e organizações desenvolvimentistas. Nas décadas seguintes, quando o discurso desenvolvimentista passou a focar questões de saúde-doença (desnutrição e mortalidade infantil), tiveram início as primeiras biopolíticas de amamentação em escala global, enquanto a prática da amamentação passa a ser operada como um meio de combater esses males.

Já o discurso de desenvolvimento social em jogo na contemporaneidade evoca também um processo de desenvolvimento individual obrado via governo de si, que busca promover a aquisição de capacidades que levem a fazer decisões ativas. Simultaneamente, as biopolíticas de amamentação recorrem a tecnologias variadas com esse propósito, e a amamentação - outrora fomentada prioritariamente entre grupos populacionais menos privilegiados - passa a ser promovida universalmente, frente aos inúmeros benefícios dessa prática que extrapolam a questão da sobrevivência na infância, constituindo-se também como um investimento para a vida adulta.

É interessante observar que, como mencionado anteriormente, a relação da desnutrição e da mortalidade infantil com o consumo de fórmulas infantis já era conhecida antes da movimentação global em prol da amamentação 16 . Ou, por exemplo, que a técnica do aconselhamento data da década de 1940, embora tenha se tornado mais proeminente a partir da década de 1960, quando se difundiu por diferentes âmbitos, como instituições de saúde e de assistência social, assim como empresas 21. Contudo, tais conhecimentos passaram a ser acionados por essa rede de entidades posteriormente, evidenciando como o discurso desenvolvimentista atua como uma referência sociocultural por meio da qual a amamentação é operada. O que permite afirmar que a amamentação é uma prática tão natural quanto política, econômica e social. 


\section{Colaboradores}

A. R. Hernandez participou da concepção do projeto e da análise e interpretação dos dados; da redação e revisão crítica relevante do conteúdo intelectual; e aprovação da versão final. C. G. Victora participou da concepção do projeto; revisão crítica relevante do conteúdo intelectual; e aprovação da versão final.

\section{Agradecimentos}

À Coordenação de Aperfeiçoamento de Pessoal de Nível Superior (Capes), pela concessão de bolsa de estudos à primeira autora durante a realização de doutorado.

\section{Referências}

1. Foucault M. Em defesa da sociedade. São Paulo: Editora Martins Fontes; 2005.

2. Rabinow P, Rose N. O conceito de biopoder hoje. Política \& Trabalho: Revista de Ciências Sociais 2006; 24:27-57.

3. Donzelot J. A polícia das famílias. Rio de Janeiro: Edições Graal; 1980.

4. Almeida JAG. Amamentação: um híbrido natureza-cultura. Rio de Janeiro: Editora Fiocruz; 1999.

5. Costa JF. Ordem médica e norma familiar. Rio de Janeiro: Edições Graal; 2004.

6. Escobar A. La invención del tercer mundo: construcción y deconstrucción del desarrollo. Caracas: Fundación Editorial El Perro y La Rana; 2007.

7. Ministério da Saúde. Semana Mundial da Amamentação (SMAM). http://portalsaude. saude.gov.br/index.php/o-ministerio/princi $\mathrm{pal} / \mathrm{secretarias} / 514$-sas-raiz/dapes/saude-dacrianca-e-aleitamento-materno/12-saude-dacrianca-e-aleitamento-materno/10378-pri meira-infancia (acessado em 23/Ago/2017).

8. World Alliance for Breastfeeding Action. World Breastfeeding Week. http://world breastfeedingweek.org/ (acessado em 23/Ago/ 2017).

9. Carvalho MR, Prochnik M. Método mãe-canguru de atenção ao prematuro. Rio de Janeiro: Banco Nacional de Desenvolvimento Econômico e Social; 2001

10. Departamento de Ações Programáticas Estratégicas, Secretaria de Atenção à Saúde, Ministério da Saúde. Atenção humanizada ao recém-nascido de baixo peso: Método Canguru. Brasília: Ministério da Saúde; 2011.

11. Fundação Oswaldo Cruz. Rede Global de Bancos de Leite Humano: a trajetória. https://rblh. fiocruz.br/pt-br/trajetoria (acessado em 23/ Ago/2017).

12. Fundo das Nações Unidas para a Infância; Organização Mundial da Saúde. Iniciativa Hospital Amigo da Criança: revista, atualizada e ampliada para o cuidado integrado. Módulo 4: autoavaliação e monitoramento do hospital. Brasília: Ministério da Saúde; 2010.

13. Secretaria de Atenção à Saúde, Ministério da Saúde. Estratégia Nacional para Promoção do Aleitamento Materno e Alimentação Complementar Saudável no Sistema Único de Saúde: manual de implementação. Brasília: Ministério da Saúde; 2015.

14. Departamento de Ações Programáticas Estratégicas, Secretaria de Atenção à Saúde, Ministério da Saúde. Atenção humanizada ao recémnascido de baixo peso: Método Canguru. Caderno do tutor. Brasília: Ministério da Saúde; 2014. 
15. Fundo das Nações Unidas para a Infância; Organização Mundial da Saúde. Iniciativa Hospital Amigo da Criança: revista, atualizada e ampliada para o cuidado integrado. Módulo 3: promovendo e incentivando a amamentação em um Hospital Amigo da Criança: curso de 20 horas para equipes de maternidade. Brasília: Ministério da Saúde; 2009.

16. Sokol E. Em defesa da amamentação: manual para implementar o Código Internacional de Mercadização de Substitutos do Leite Materno. São Paulo: Rede Internacional em Defesa do Direito de Amamentar; 1999.

17. Monteiro R. Norma brasileira de comercialização de alimentos para lactentes e crianças de primeira infância: histórico, limitações e perspectivas. Rev Panam Salud Pública 2006; 19:354-62.

18. Araújo MFM. Situação e perspectivas do aleitamento materno no Brasil. In: Carvalho MR, Tamez R, organizadores. Amamentação: bases científicas. Rio de Janeiro: Editora Guanabara Koogan; 2005. p. 269-81.

19. Rea MF. Reflexões sobre a amamentação no Brasil: de como passamos a 10 meses de duração. Cad Saúde Pública 2003; 19 Suppl 1:S3745.

20. Arcoverde D. ONGs, redes e movimentos sociais em aleitamento materno. In: Carvalho MR, Tamez R, organizadores. Amamentação: bases científicas. Rio de Janeiro: Editora Guanabara Koogan; 2005. p. 302-14.
21. Zen ET. Princípios do aconselhamento aplicados ao assistir em amamentação na perspectiva dos profissionais de saúde [Dissertação de Mestrado]. Rio de Janeiro: Instituto Fernandes Figueira, Fundação Oswaldo Cruz; 2001.

22. Bueno LGS, Teruya KM. Aconselhamento em amamentação e sua prática. J Pediatr (Rio J.) 2004; 80(5 Suppl):S126-30.

23. Goldenberg P. Repensando a desnutrição como questão social. São Paulo: Editora Cortez; 1989.

24. Faé R. Os discursos sobre desenvolvimento como recursos político-estratégicos: o Banco Mundial como organização central no campo discursivo do desenvolvimento [Tese de Doutorado]. Porto Alegre: Escola de Administração, Universidade Federal do Rio Grande do Sul; 2009.

25. Sen A. Desenvolvimento como liberdade. São Paulo: Companhia das Letras; 2010.

26. Tornquist CS. Paradoxos da humanização em uma maternidade no Brasil. Cad Saúde Pública 2003; 19 Suppl 2:S419-27.

27. Coelho MC, Sento-Sé JT, Fernandes RB, Rios F. A experiência da sujeição à autoridade policial: notas sobre a articulação entre cognição e emoção na vida pública. Rev Bras Ciênc Soc 2016; 31:151-66. 


\section{Abstract}

This study aimed to analyze the links between the production of biopolitics for breastfeeding and social development discourses after the post-war period, with a view towards problematizing the nature/culture dichotomy by which breastfeeding is often operationalized. The study adopts an anthropological perspective to compare biopolitics for breastfeeding with the changes in developmentalist discourses. The analysis of global movements by these biopolitics helped explain how a network of distinct entities (e.g., government agencies, multilateral bodies, international development agencies, and nongovernmental organizations) have shaped breastfeeding over time in keeping with the prevailing developmentalist discourses and practices. Initially, the developmentalist discourse focused on industrialization and modernization, and breastfeeding was not the focus of public policies. In the 1970s and 1980s, when the developmentalist discourse shifted the focus to child malnutrition and infant mortality, the first global biopolitics for breastfeeding were launched, and breastfeeding practice began to be operationalized as a means to fight these health problems. Meanwhile, the contemporary social development discourse also evokes a process of individual development. Simultaneously, biopolitics for breastfeeding rely on various technologies for this purpose. The conclusion is that developmentalist discourses act as a sociocultural reference by which breastfeeding is operationalized, and thus that breastfeeding is not only a natural process, but also a political, economic, and social one.

Breast Feeding; Social Change; Public Policy

\section{Resumen}

El objetivo de este artículo ha sido analizar los vínculos entre la generación de biopoliticas en lactancia materna y los discursos existentes sobre desarrollo social, tras el período de posguerra, relacionados con la problematización de la dicotomía naturaleza/cultura, a través de la cual transita frecuentemente lactancia materna. Desde una perspectiva antropológica, se examinaron comparativamente biopoliticas en lactancia materna con transformaciones surgidas en los discursos desarrollistas. El examen de los movimientos globales, realizados por esas biopolíticas, permitió comprender cómo una red de entidades variadas (como órganos de gobierno, organismos multilaterales, agencias internacionales de desarrollo y organizaciones no gubernamentales) han considerado a lo largo del tiempo la lactancia materna, según los discursos y prácticas desarrollistas en vigor. Inicialmente, el discurso desarrollista giraba en torno a la industrialización y modernización, y la lactancia materna no era el centro de atención de las políticas públicas. En las décadas de los 1970 y 1980, cuando el discurso desarrollista pasó a centrarse en la desnutrición y la mortalidad infantil, comenzaron las primeras biopolíticas globales en lactancia materna y la práctica de la lactancia pasó a ser tratada como un medio de combatir tales males. Ya el discurso de desarrollo social en boga en la contemporaneidad evoca también un proceso de desarrollo individual. Simultáneamente, las biopolíticas en lactancia materna exploran tecnologías variadas con este propósito. Se concluye que los discursos desarrollistas actúan como una referencia sociocultural, basándose en cómo es operada la lactancia materna, lo que permite considerarla una práctica tan natural, como política, económica y social.

Lactancia Materna; Cambio Social; Política Pública
Recebido em 05/Set/2017

Versão final reapresentada em 30/Abr/2018

Aprovado em 25/Mai/2018 